\title{
Monitoring open stope caving at Goldex Mine
}

\author{
M.R. Hudyma Laurentian University, Canada \\ P. Frenette Agnico-Eagle Mines Limited, Canada \\ I. Leslie Engineering Seismology Group, Canada
}

\begin{abstract}
Goldex is a sublevel open stoping mine near Val-d'Or in northwestern Quebec. The orebody will be extracted in stages, using a novel mining method, resulting in a single stope with the dimensions of $450 \mathrm{~m}$ on strike, $250 \mathrm{~m}$ in height and up to a width of $120 \mathrm{~m}$. A microseismic monitoring system was designed to monitor the profile of the large stopes and the extent of overbreak around the stopes. This paper discusses the design of the seismic system, and the results of the seismic monitoring with regard to observations of stope performance. In particular, the paper discusses how the seismic source parameter Apparent Stress can be used to identify areas of active rock mass fracturing.
\end{abstract}

\section{Introduction}

The Goldex Mine is a 7,000 tpd gold mine which achieved commercial production in August 2008. In order to monitor the profile of the large open stopes created, many instrumentation types are used, including extensometers, sloughmeters, laser surveys and a seismic system. The latter has proven the most useful in understanding the behaviour of the rock mass.

\subsection{Goldex orebody and geological setting}

The Goldex Mine is a gold mine located $4 \mathrm{~km}$ west of the town of Val-d'Or in the Abitibi region of northwest Quebec. It is part the southeastern portion of the Abitibi Subprovince, a typical granite-greenstone terrane and part of the Superior Province of the Canadian Shield. The Goldex deposit is located at a depth of $750 \mathrm{~m}$ below ground surface and is hosted within a quartz diorite sill located in a package of mafic to ultramafic volcanic rocks. The geology is oriented generally N280 and dips 75-85 degrees to the north. The major geological domains are granodiorite which host the quartz-tourmaline gold bearing veins; basalt, located both on the north and south of the granodiorite; mylonite and komatiite shears, also located both north and south of the granodiorite and small diabase dykes cutting the orebody at an almost perpendicular angle. Additional details about the geological setting can be found in Frenette (2010).

\subsection{Mining method}

To be able to economically mine the orebody, a bulk mining method had to be used. A block caving method was originally considered, but because of the high quality of the rock mass, numerical modelling suggested the cave would choke itself before the orebody was completely recovered. A new mining method, as productive as block caving, with low mining costs had to be developed. The orebody was divided in three stopes each consisting of sublevels about $80 \mathrm{~m}$ apart (Figure 1). Each sublevel is drilled and blasted in a sequence where the extremity stopes are blasted first and a central stope is mined at a later stage. In the first stages, only the swell of the blasted ore is extracted, the objective being to leave as much ore as possible in the stopes to act as support for the walls. Once the orebody is completely blasted, the ore is removed from the lowest level and any dilution coming from the roof or walls is left on top of the ore. This new mining method, named long hole shrinkage, uses concepts from different mining methods such as:

- the high efficiency haulage level of a block cave operation

- wall stability of a shrinkage stoping method

- fragmentation of a long hole stoping method

- large blast and mucking flexibility of a vertical crater retreat (VCR) method. 


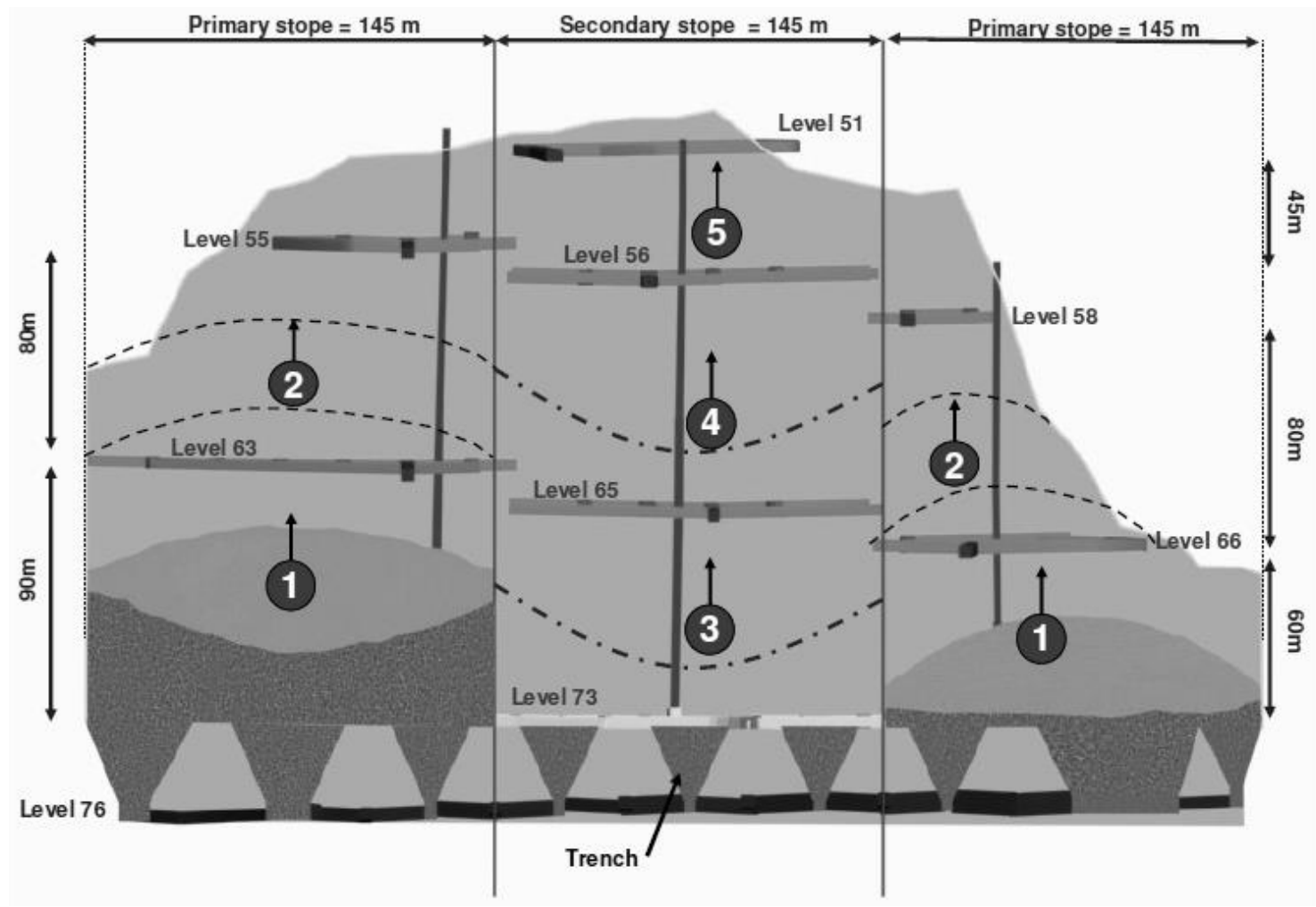

Figure 1 Goldex mining method and extraction sequence

\section{Goldex seismic monitoring system}

Extraction of the Goldex orebody uses a novel and aggressive open stoping mining method. It was felt that a high-resolution seismic monitoring system would be essential to monitor the rock mass response to mining to ensure that the large open stopes were behaving as expected.

\subsection{Seismic monitoring objectives and requirements}

There were four primary objectives for the seismic monitoring system at Goldex:

1. Stope back monitoring. One of the primary objectives of the seismic monitoring system was to monitor for locations of stress change following mine blasts and identify the location of the back of the large open stopes. It was expected that significant failure would occur in the backs and walls of the open stopes, and that the seismic monitoring system would provide real-time information about any major sloughing around the open stopes.

2. Monitor stability of major infrastructure in the mine. The seismic system was designed to reliably locate seismicity occurring near the orebody crusher, maintenance workshop and shaft areas.

3. Monitor main production areas of the mine. While rockbursting is not anticipated at Goldex, the seismic system should be able to identify high stress related hazards in the mine drawpoints, the main central pillar and near the internal ramp in the footwall of the orebody.

4. Effect of mining on mine-wide geological features. There are mine-wide faults in the footwall and hangingwall of the orebody. These features intersect some of the key infrastructure of the mine. One of the objectives of the seismic system was to monitor for any movement or failure along those features during mining of the Goldex orebody.

To meet the monitoring objectives for the Goldex Mine, a high resolution seismic monitoring system was designed. Specific features of the system that were desired included: 
- a high sensor density so that very small seismic events could be recorded

- accurate locations, requiring a good three dimensional array of sensors surrounding the areas of interest

- a sufficient number of triaxial sensors so that seismic source parameters such as seismic energy and seismic moment could be reliably calculated.

The Goldex seismic array is composed of uniaxial and triaxial accelerometers. Mine development around the Goldex orebody provided excellent locations for seismic sensors. Ideally, a seismic array surrounds the monitoring region of interest. This is particularly the case for Goldex, in which sensors could be located in footwall development, hangingwall development, as well as development to the east and west of the mine (up and down strike).

\subsection{Engineering Seismology Group's Paladin seismic monitoring technology}

Engineering Seismology Group's (ESG) Paladin acquisition system provides continuous monitoring of seismicity generated by man-made operations and is especially suited for recording seismic events induced by mining activity. The 24-bit Paladin acquisition units are rugged, low powered, web-enabled, six channel devices that can operate as standalone units or in a multi-station configuration with a local area or remote wireless network. These individual acquisition units are typically connected to strategically located sensors where the analogue output signals are digitised (Figure 2).

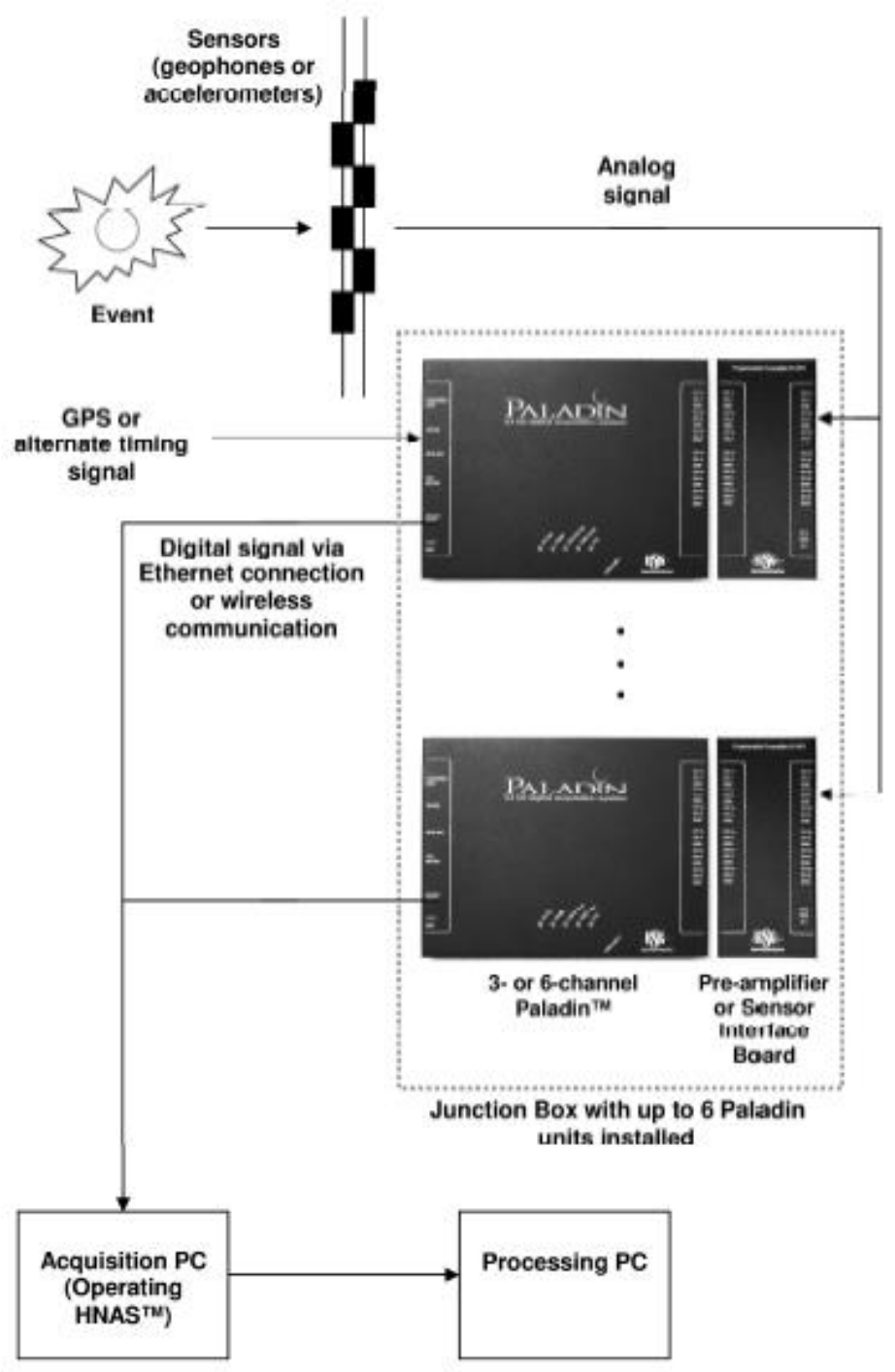

Figure 2 General schematic showing typical data flow for a network of Paladin stations 
From the Paladin acquisition stations, signals are sent digitally along a network backbone to an acquisition PC on surface where continuous data from all sensors are written to disk. Filtering and trigger logic is used to identify possible seismic events, which are transferred to a processing PC and processed to provide source location, magnitude and other source parameters. Time synchronisation of distributed Paladins is achieved either with direct GPS timing from satellites (in the case of surface systems) or via a timing fibre which injects GPS and pulse per second information underground to each Paladin unit. The system provides exceptional monitoring capabilities, automatically recording and displaying continuous seismograph traces to the user at the central processing PC in the engineering office in real time. Additionally, because many days of seismic data are recorded continuously, the system allows the user to adjust trigger logic settings, and reprocess data from critical periods in the past, to possibly identify more seismic activity.

The ESG system installed at Goldex is comprised of six Paladins (36 channels) with two Paladins located on 38, 60 and 73 levels respectively (Figure 3). The system is connected to uniaxial and triaxial accelerometers installed underground and the sampling frequency used for recording is $20 \mathrm{KHz}$. Low loss optic fibre communication is used, with two fibres providing data networking between the Paladins and the surface acquisition PC, and a third fibre for synchronising the underground Paladins with the GPS timing server on surface.

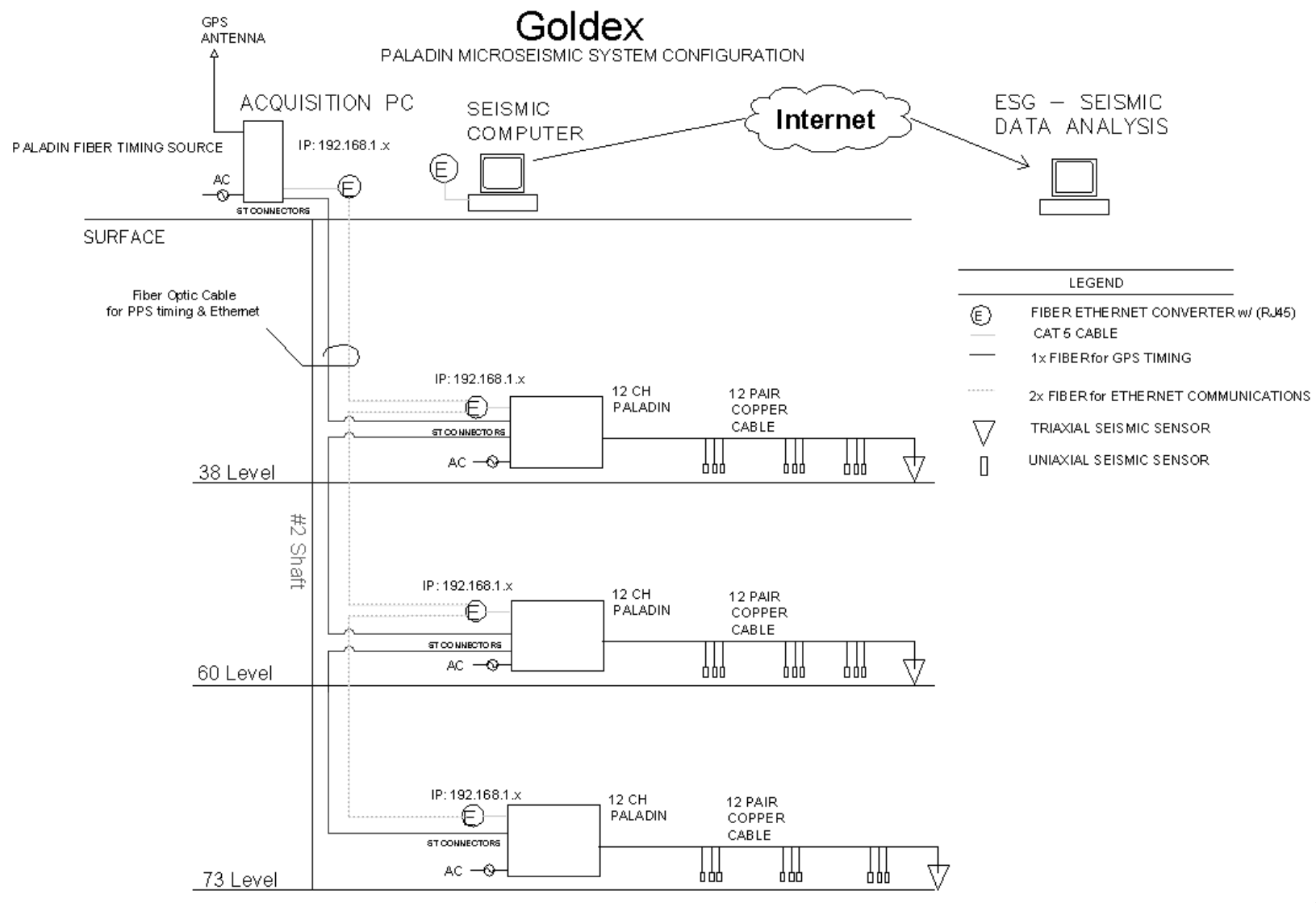

Figure 3 Schematic of the Goldex microseismic system

\subsection{Goldex seismic system design}

Prior to the installation of the Goldex sensor array, a preliminary array design was conducted in order to optimise the location of the sensors underground. As part of the design, an errorspace modelling analysis was completed to provide estimates of theoretical location errors within the monitoring region and to determine minimum detectible magnitude for the array. The analysis assumed a final array configuration of 28 sensors (four triaxials and 24 uniaxials) installed between $-742 \mathrm{~m}$ and $-327 \mathrm{~m}$ elevations. It assumed an average P-wave velocity estimate of $6,000 \mathrm{~m} / \mathrm{s}$ (typical velocity of hard rocks in the Canadian Shield) and a $2 \%$ variance in the velocity. Only the 10 closest sensors were used for the theoretical events in order to simulate the real case in which only a fraction of the total available sensors record the events. The observed P-wave 
arrival time errors were assumed to be random, have a Gaussian distribution with zero mean and a standard deviation of $1.5 \mathrm{~ms}$. S-wave arrivals were not considered in the analysis because the goal was to simulate the automatic case, in which only P-wave arrivals are picked by the system.

The results of this analysis indicated that the Goldex array in its final configuration would be expected to have total location errors of $15 \mathrm{~m}$ or better within the sensor array volume (Figure 4) and would record events as low as -2.5 moment magnitude. The errorspace is smoothly varying without any local minima. As expected, the location accuracy is highest in the central core of the array, with an average error of approximately $4 \mathrm{~m}$.

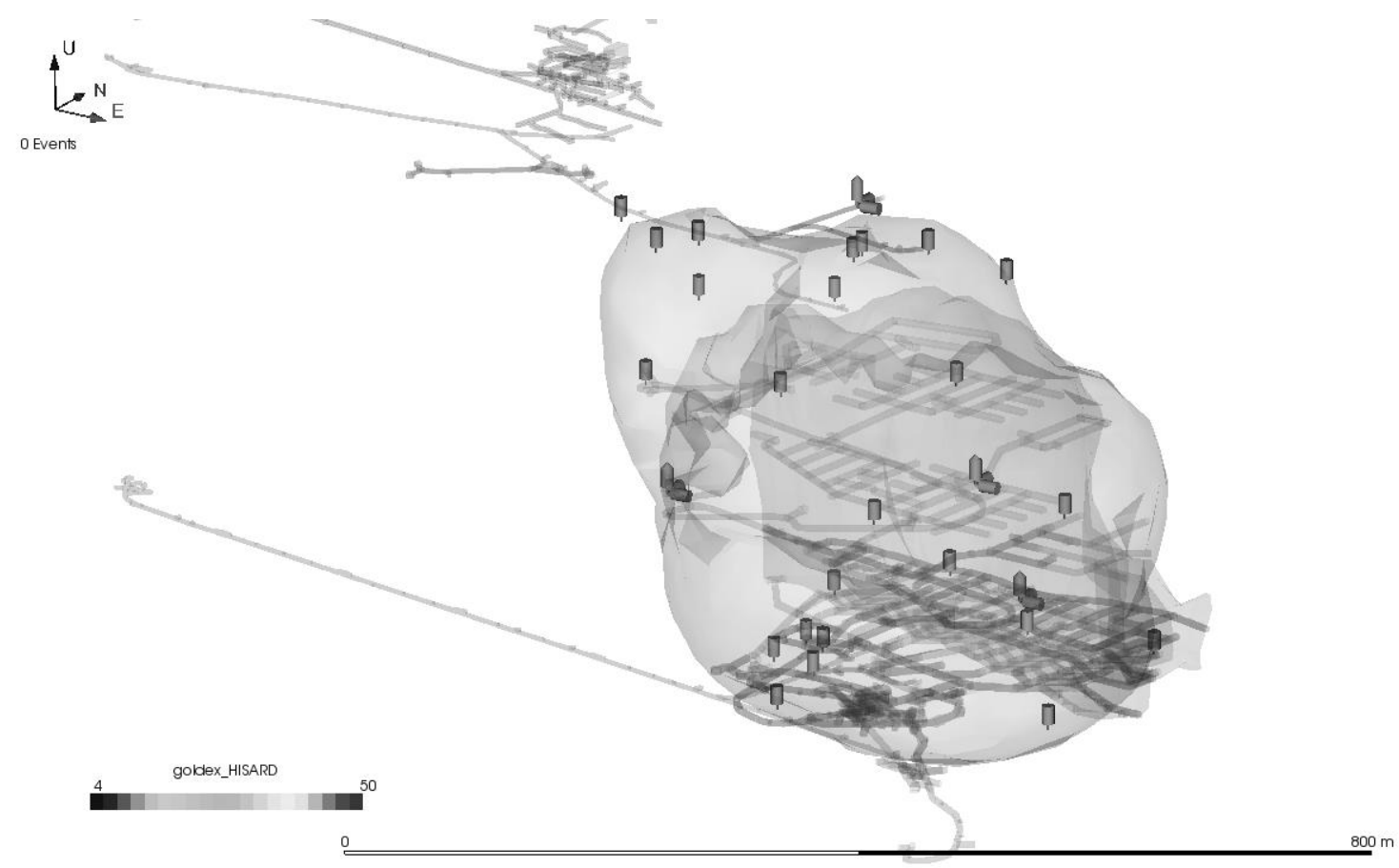

Figure 4 Location errorspace results are plotted as a 3D iso-surface ( $15 \mathrm{~m}$ location error) superimposed on the mine workings. The sensor locations are shown as grey cylinders. The results of the errorspace analysis indicated that the event locations within the array recorded by a minimum of $\mathbf{1 0}$ sensors would be expected to have theoretical location errors of 4-15 m

For the events occurring within the limits of the sensor array between April and November 2009 (Figure 5), the average location error is $8.6 \mathrm{~m}$ and the median error is $5.2 \mathrm{~m}$ as estimated from travel time residuals by the seismic processing software.

\section{Seismic monitoring results to date}

The locations of recorded microseismic event have proven to be very accurate, with errors in the range of only a few metres. The system is also detecting events near moment magnitude -2 , giving the level of sensitivity originally sought. This high quality microseismic data provides a rock mass monitoring system identifying important rock mechanics information, including: depth of stope back and stope wall overbreak, areas stress change, and a differing rock mass response to mining between the west and East stopes.

\subsection{Stope back profiles}

The microseismic event locations outline the profile of the stopes. In Figure 6 (left), the locations of microseismic events are shown in the week prior to a stope blast in the East stope. The events follow closely to the surveyed shape of the stope. Following a production blast on 1 June 2009, more than 1,000 seismic events were located around the East stope, in the first four hours following the blast Figure 6 (right). The events showed a clear profile between 30 and $50 \mathrm{~m}$ above the previous stope profile. A laser survey was 
conducted, with the events matching closely to the new shape of the surveyed stope (the surveyed shape is shown with a dark wireframe in Figure 6 right).

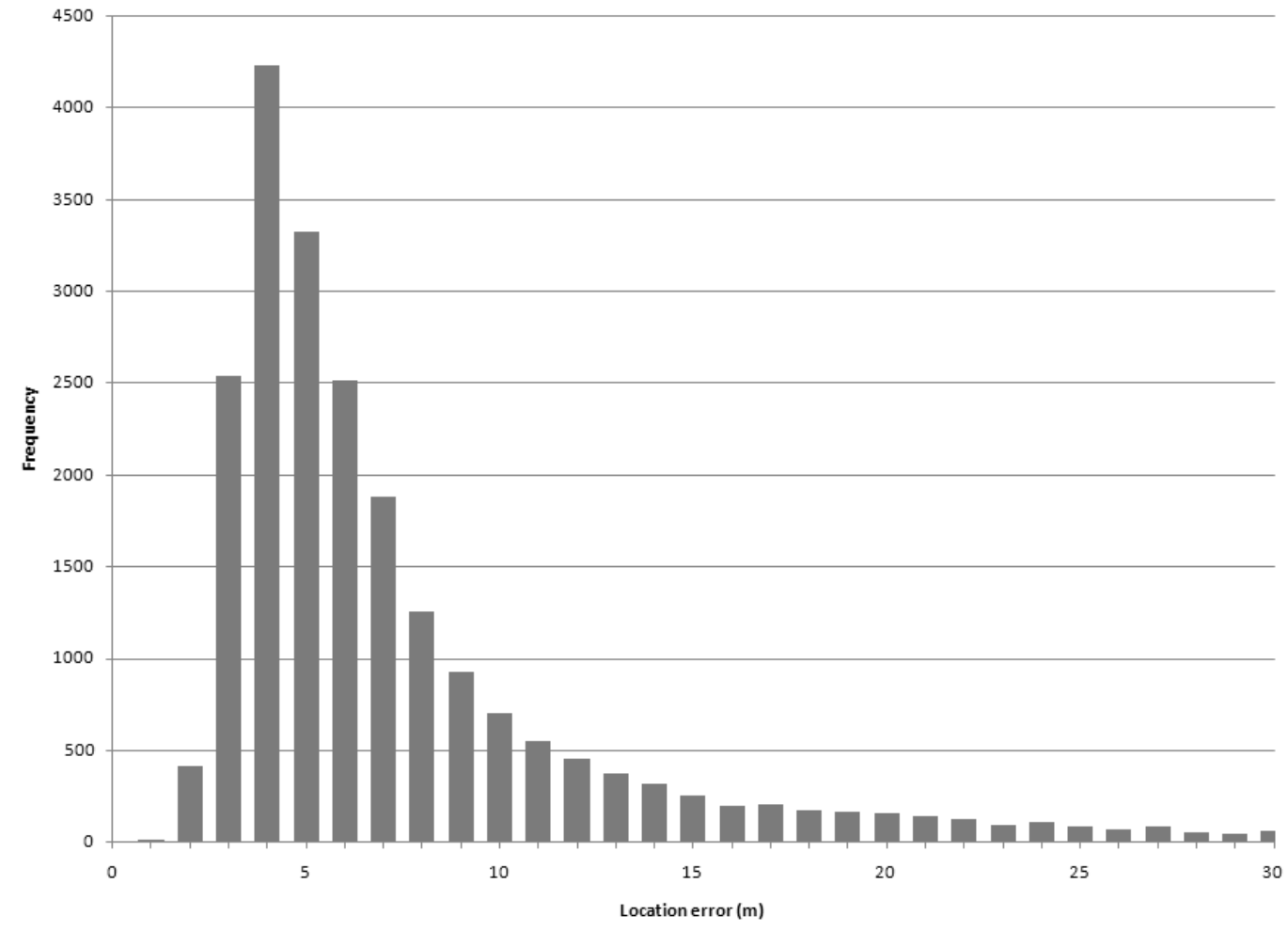

Figure 5 Distribution of estimated location errors from actual data recorded by the system between April and November 2009. These locations were determined from automatically picked data and also include recordings of blasting
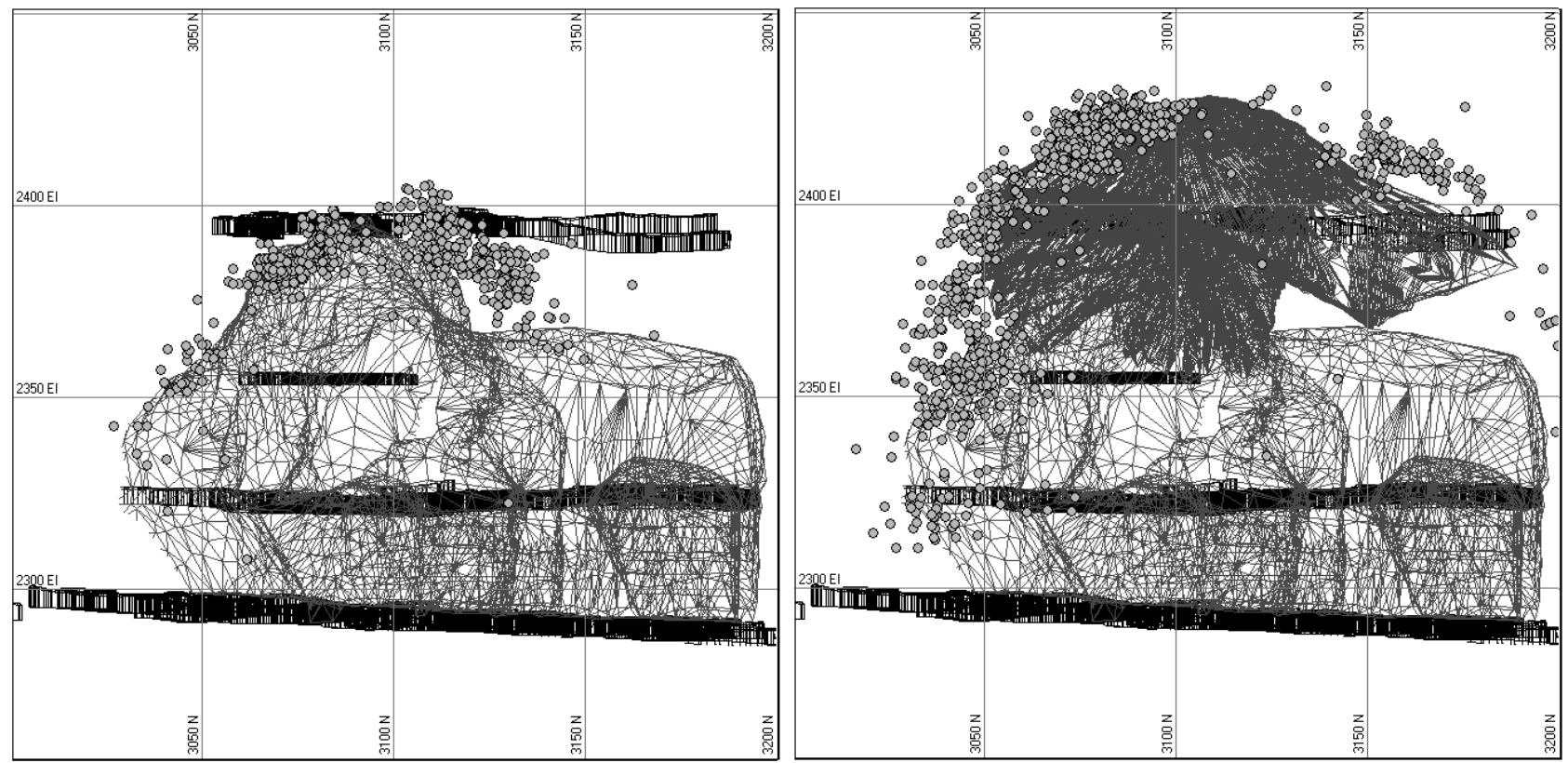

Figure 6 Locations of seismic events before and after a production blast, profiling the shape of the East stope (the dark wireframe on the right is the surveyed stope shape follow the blast) 


\subsection{Failure in stope walls}

During stope blasting in mid 2009, significant numbers of seismic events were recorded in the footwall of the East stope, in the vicinity of the main service ramp in the mine. With successive stope blasts the failure front of events moved closer to the ramp. Diamond drilling showed that fractured ground started at a distance of $60 \mathrm{~m}$ from the ramp, or about $8 \mathrm{~m}$ in from the previously measured wall profile. The fractured ground relates well to the location of the highest density of microseismic events (Figure 7).

At this time, there is no visible effect of the seismicity on the rock mass conditions and stability of the main ramp, however, the microseismic system is providing valuable information to show where the fracturing is currently occurring, and whether that fracturing is gradually moving towards the ramp.
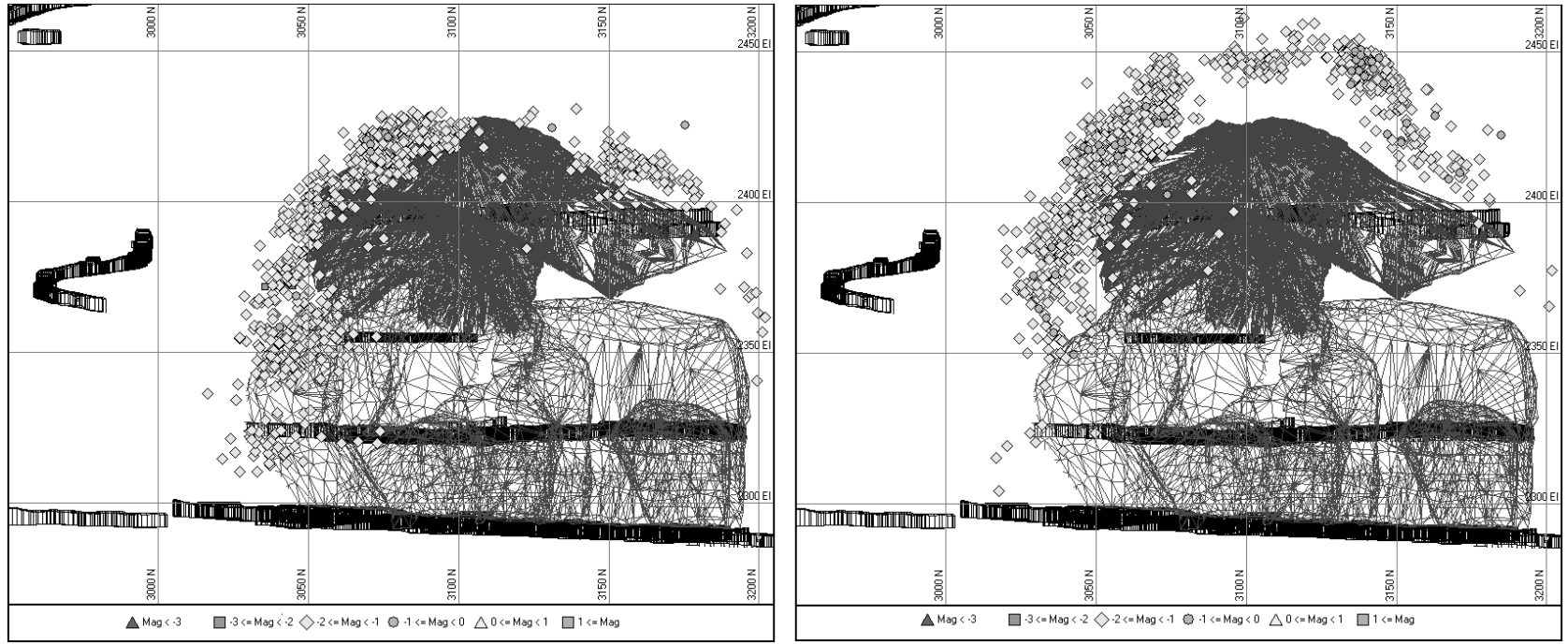

Figure 7 Events in the footwall of the East stope following a mine blast on 1 June 2009 (left) and 23 June 2009 (right)

\subsection{Active stress change}

Apparent Stress is a model independent measure of the stress change at a seismic source (Wyss and Brune, 1968). Apparent Stress can be used as an indicator of the relative level of stress at the source of a seismic event (Mendecki, 1993; Hudyma, 2008).

Following production blasts at Goldex, it was observed that the Apparent Stress of seismic events was significantly higher than before the blast. Figure 8 shows seismic events in the three weeks preceding a production blast (left) and in the 24 hours after a production blast (right). Figure 8 shows the Apparent Stress is considerably higher following the mine blast. This is particularly obvious in the events that follow the stope back profile. It is interpreted that higher than expected Apparent Stress is associated with areas in which active stress fracturing of the rock mass is underway. Similar observations have been made in longwall, open stoping and caving mines (van Aswegen and Butler, 1993; Simser et al., 2003; Hudyma et al., 2008).

\subsection{Different rock mass behaviours for two stopes}

To date, there is a significant level of microseismicity recorded around each of the two partially extracted stopes at Goldex. However, the seismic response to mining around the West stope is considerably different compared to the seismic response to mining around the East stope. The main reason for the difference is there is a series of weak dykes which crosscut the orebody. When the dykes are close to the boundary of the West stope, there is considerable rock mass deterioration observed near the dykes. This deterioration is detected by the seismic system as a higher background rate of microseismic events between production blasts. No weak geological features have been identified in close proximity to the East stope. The following section characterises some of the seismological differences between the two stopes. 

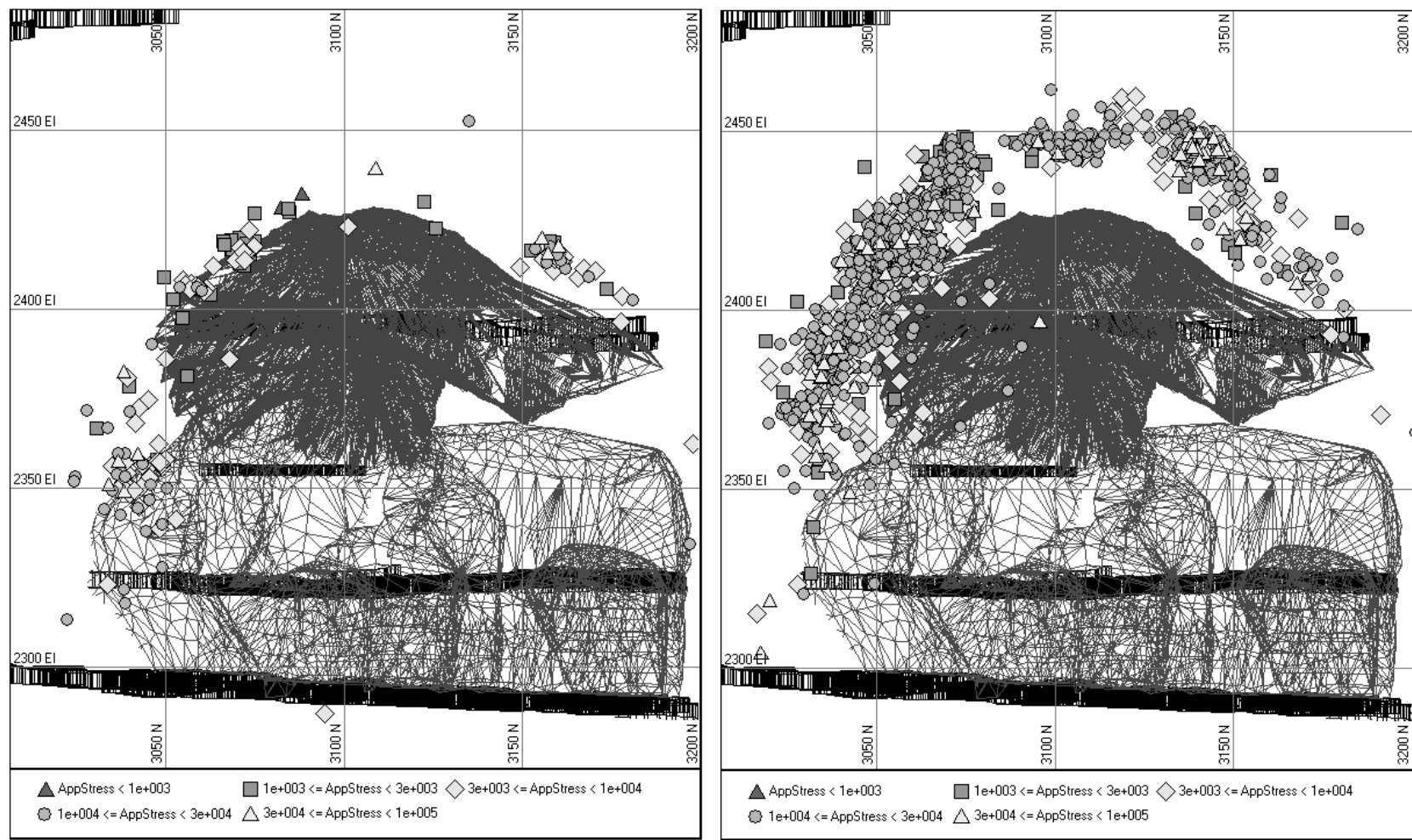

Figure 8 Seismic events (plotted by Apparent Stress) in the three weeks prior to a stope blast (left) and in the day following a stope blast in the East stope (right)

\subsubsection{East stope}

The microseismicity recorded around the East stope is almost exclusively associated with stress change due to mine blasting. Figure 9 shows the location of seismic event following a mine blast on 21 April 2009.

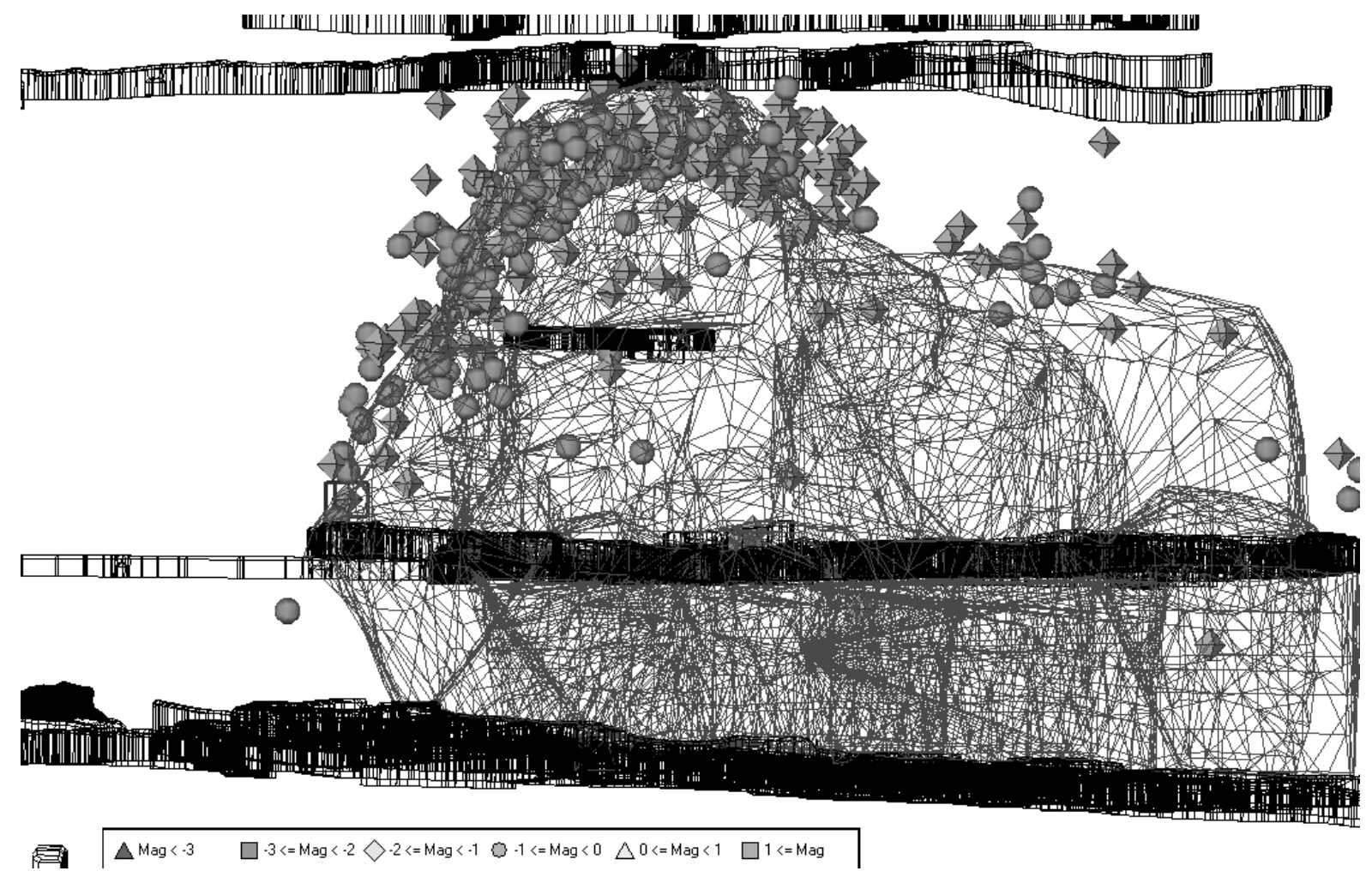

Figure 9 Microseismic events occurring directly following a production blast in the East stope 
The events are located directly on the stope boundary. The rate of events decreases quickly after the stope blast with subsequent events also occurring on the stope boundary. Essentially, there is minimal overbreak being observed between production blasts in the East stope. A magnitude-time history of the events (Figure 10) shows the timing of events following typical stope blasts on 21 April, 14 May, 21 May and 23 May. The event rate typically decreases to background levels within a couple of hours of the blast.

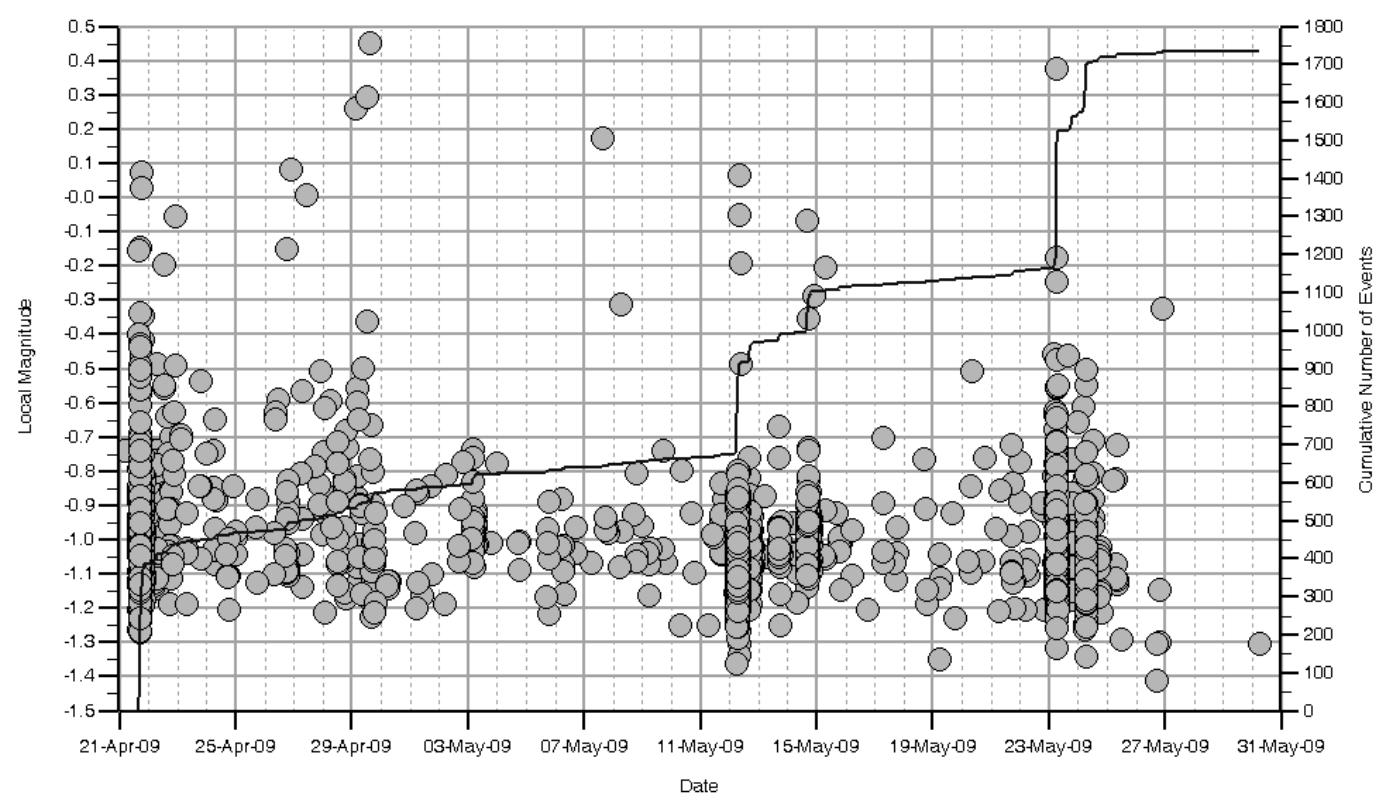

Figure 10 Magnitude-time history plot of the events following a production blast in the East stope

The cumulative distribution of S:P energy ratio of the events around the East stope is shown in Figure 11 (left). The S:P energy ratio has a similar distribution compared to the rest of the mine. The distribution of S:P energy ratio showed no dependence on event magnitude.
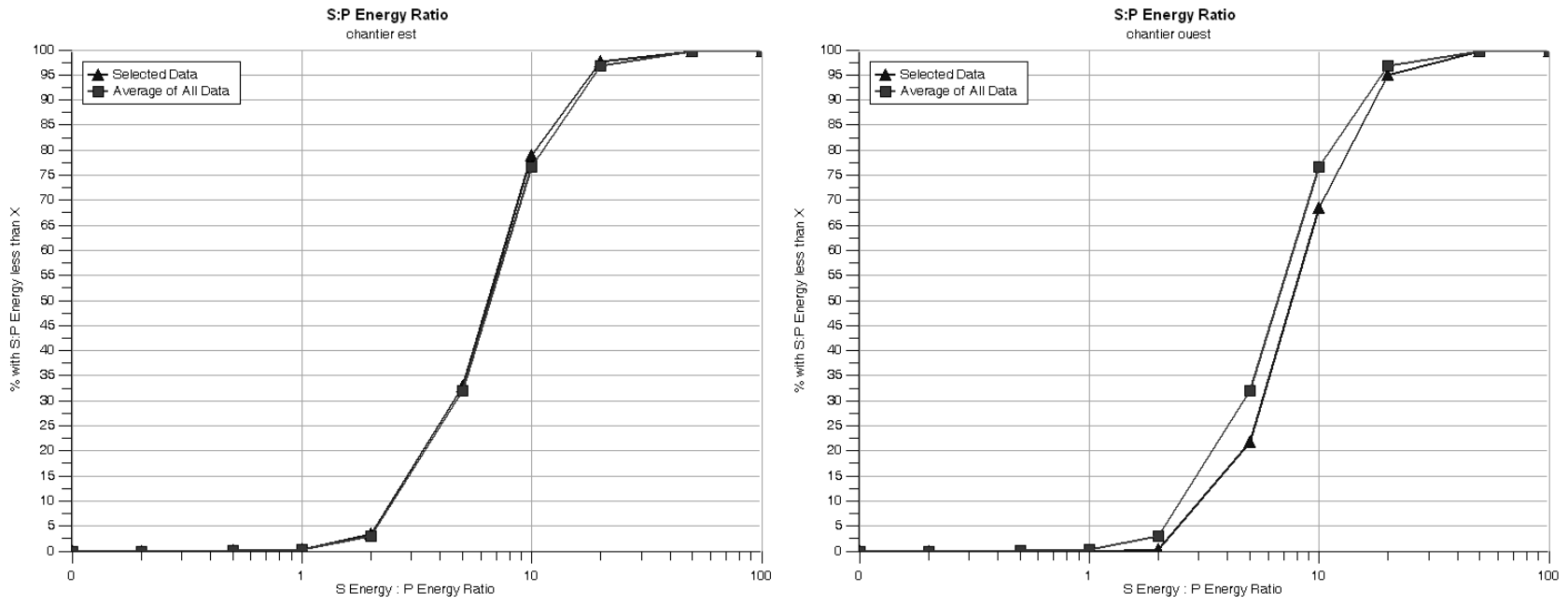

Figure 11 S:P energy ratio analysis of events around the East stope (left) and West stope (right)

\subsubsection{West stope}

A longitudinal projection of the West stope is shown in Figure 12. The locations of the events that occurred over a period of five weeks form a cloud above the stope back. The same events are shown in cross section in on a week by week basis in Figure 13. The elevations of the events increase over time, somewhat independent of production blasting. It is believed that weak dykes are responsible for a time dependent failure causing a gradual increase in elevation of rock mass fracturing (and event locations). 


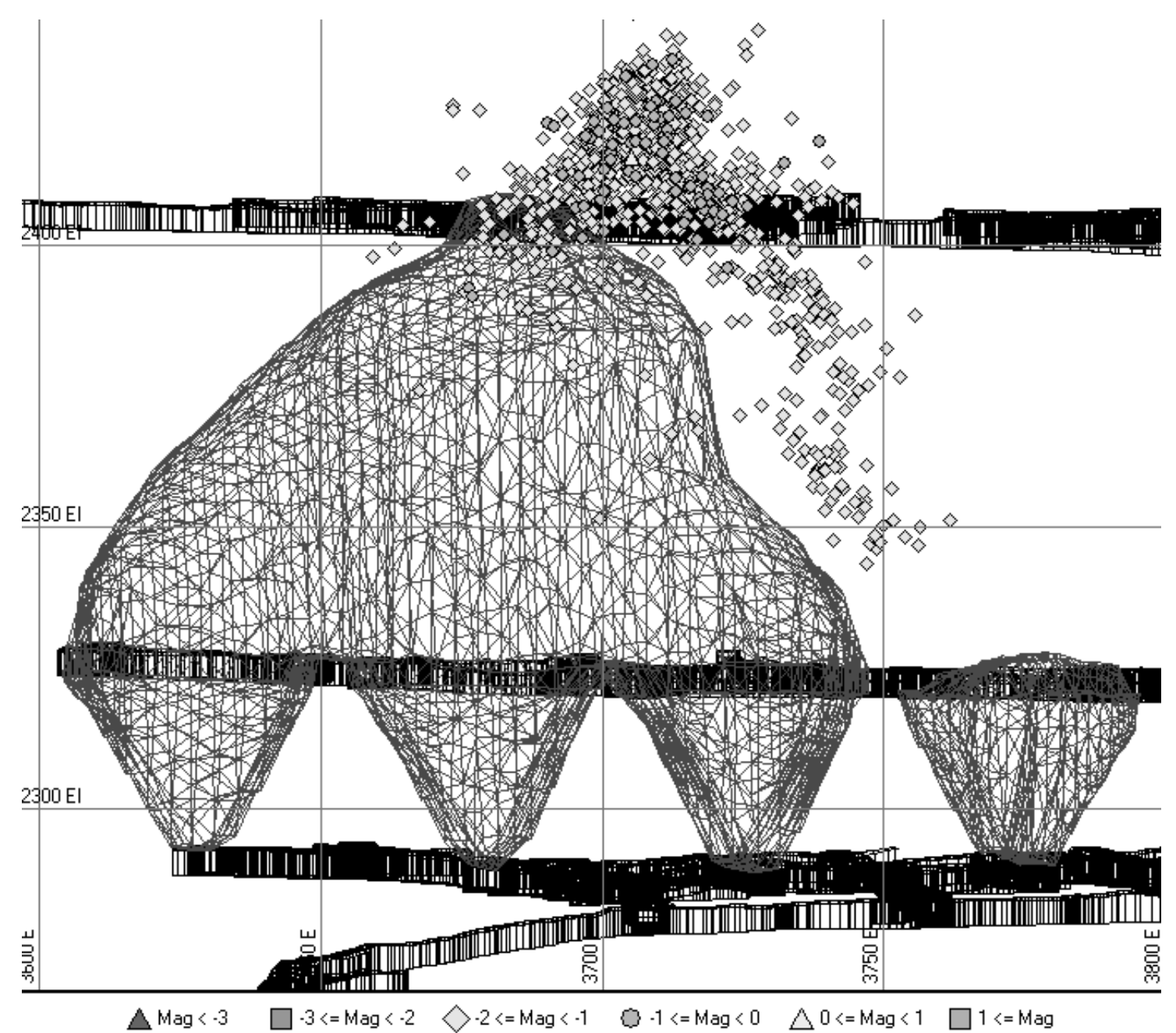

Figure 12 Event locations in the weeks following a production blast in the West stope
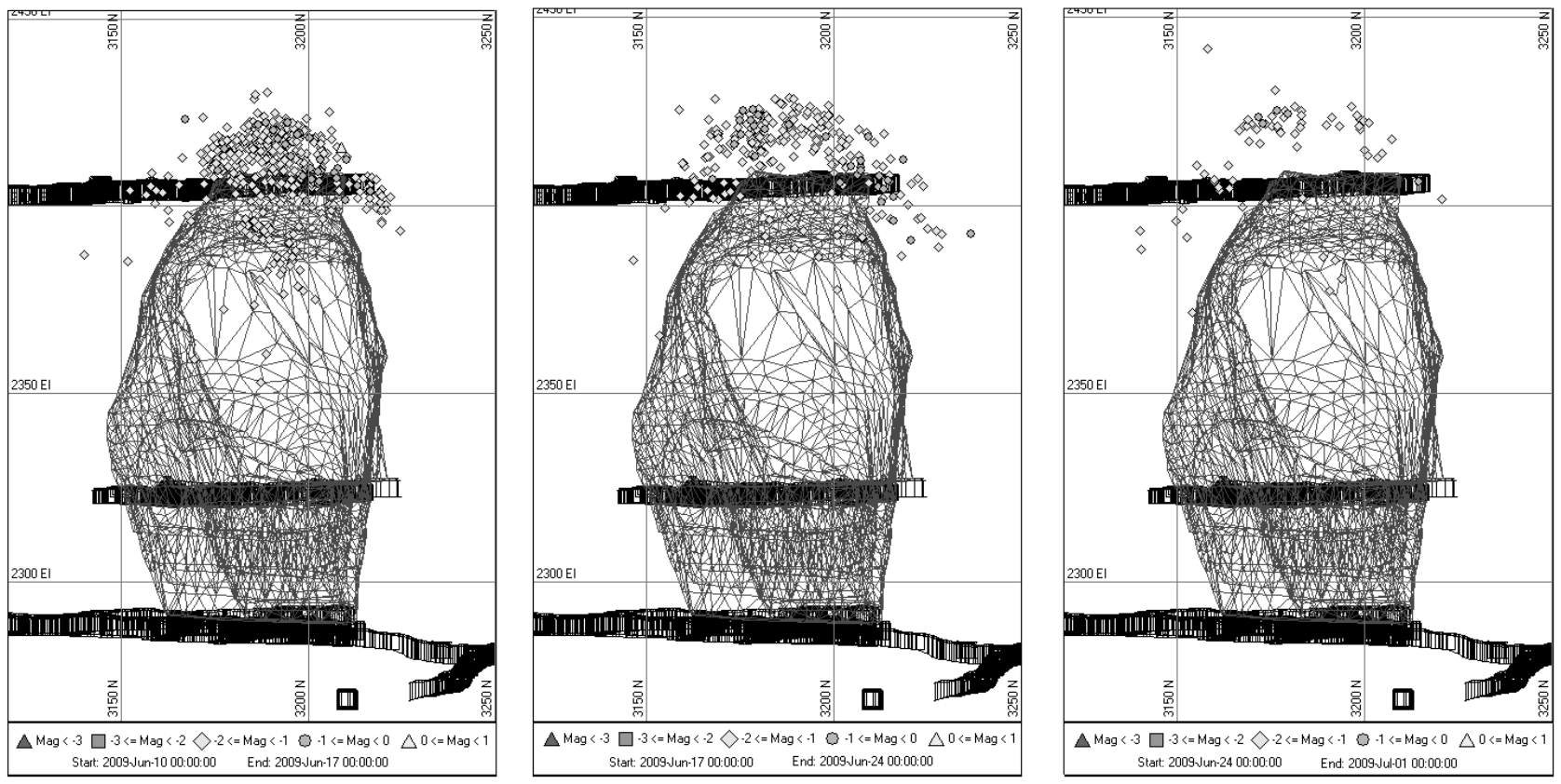

Figure 13 Week by week event locations above the West stope, showing a gradual increase in the elevation of the seismicity 
A magnitude-time history chart for the three week period (in Figure 13) is shown in Figure 14. While the rate of event directly following stope blasts is high, there is a significant event rate between stope blasts (in contrast to the low event rate in the East stope between production blasts). This higher post-blast event rate reflects the fact that some of the seismicity is associated with failure of minor geological features. This can also be observed in the distribution of S:P energy ratio with the West stope, with the events generally having a higher S:P energy ratio compared to the East stope (Figure 11).

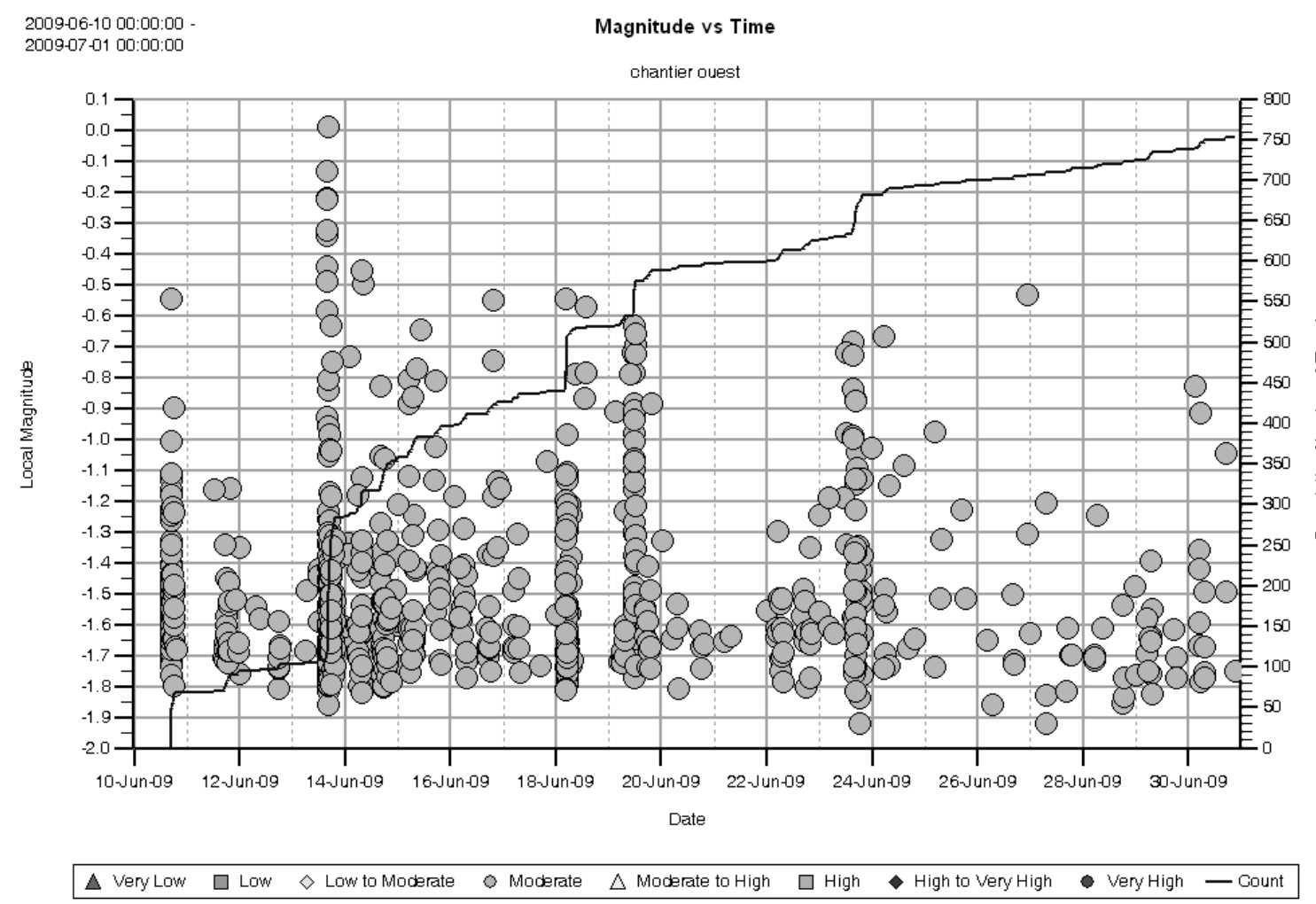

Figure 14 Magnitude-time history plot of the events following a production blast in the West stope

\section{$4 \quad$ Summary and conclusions}

The Goldex seismic monitoring system was designed to detect microseismic events down to moment magnitude -2 . This would allow the system to act as a rock mass monitoring system, helping to monitor the stope back shape, overbreak in stope walls, and the infrastructure areas of the mine. The system has achieved those objectives, becoming an integral rock mechanics monitoring tool at Goldex Mine.

\section{Acknowledgements}

The authors wish to thank the management of Agnico-Eagle Mines Limited for permission to publish this paper.

\section{References}

Frenette, P. (2010) The Goldex Mine mining method, in Proceedings Second International Symposium on Block and Sublevel Caving, Australian Centre for Geomechanics, Perth, Australia (in press).

Hudyma, M.R. (2008) Analysis and Interpretation of Clusters of Seismic Events in Mines, Unpublished Ph.D. Thesis, University of Western Australia, $365 \mathrm{p}$.

Hudyma, M.R., Potvin, Y. and Allison, D. (2008) Seismic Monitoring of the Northparkes Lift 2 Block Cave - Part 1 Undercutting, SAIMM Journal, Vol. 108, No. 7, pp. 405-419.

Mendecki, A.J. (1993) Real time quantitative seismology in mines, in Proceedings Rockbursts and Seismicity in Mines, Kingston, August 1993, R.P. Young (ed), Rotterdam: A.A. Balkema, pp. 287-295.

Simser, B.P., Falmagne, V., Gaudreau, D. and MacDonald, T. (2003) Seismic response to mining at the Brunswick mine, Canadian Institute of Mining and Metallurgy Annual General Meeting, Montreal, 12 p. 
van Aswegen, G. and Butler, A.G. (1993) Applications of quantitative seismology in South African gold mines, in Proceedings Rockbursts and Seismicity in Mines, Kingston, August 1993, R.P. Young (ed), Rotterdam, A.A. Balkema, pp. 261-266.

Wyss, M. and Brune, J.N. (1968) Seismic moment, stress and source dimensions for earthquakes in the CaliforniaNevada region, Journal of Geophysical Research, Vol. 73, pp. 4681-4694. 